\title{
NEOLIBERALISMO E EDUCAÇÃO: NOTAS DE UMA RACIONALIDADE EXCLUDENTE
}

\author{
RobSOn GUEDES DA SiLVA \\ Ana Flor Fernandes Rodrigues \\ Diogo Pedro da Silva Fernandes \\ Karina Mirian da Cruz Valença Alves \\ Universidade Federal de Pernambuco (UFPE), Recife, Pernambuco, Brasil
}

\begin{abstract}
RESUMO: Este ensaio teórico objetiva problematizar o neoliberalismo a partir das contribuições de Michel Foucault, compreendendo-o como uma racionalidade que articula uma sofisticação do poder biopolítico. Se lança a tecer notas que almejam problematizar os recentes acontecimentos no nosso país, percebendo cada vez mais pautas neoliberais se alargando dentro do campo da educação sob os signos do progresso e da inovação, em que o "Future-se" e os "Novos Caminhos", enquanto programas neoliberais bolsonaristas, de um lado, articulam a defesa de uma privatização e a desnacionalização da educação pública e, do outro, fomentam ideários e práticas conservadoras e autoritárias.
\end{abstract}

Palavras-Chave: Neoliberalismo. Educação. Conservadorismo. Foucault.

\section{INTRODUÇÃO}

O neoliberalismo, desde a década de 1970, foi se conformando como uma racionalidade, uma forma de governo, um conjunto de práticas políticas e econômicas que vão mobilizar, principalmente, uma posição ideológica de direita que se desloca do liberalismo clássico ou ordoliberalismo. Seu primeiro laboratório passou a funcionar somente através de uma ruptura abrupta com o sistema democrático do Chile em 1973, quando Pinochet, junto com outros militares, derrubou o governo Allende.

Gestado na Escola de Chicago, um projeto parecido ao do período totalitário é vendido como solução inovadora para um país como Brasil, ainda imerso em variadas formas de desigualdade social, a proposta salvadora é, além de privatizações e reformas estatais, no campo da educação, produzir subjetividades. Dado isso, e Escola de Chicago introjeta como um dos principais pilares à teoria do Capital Humano, pois este "[...] referese a um conjunto de habilidades, capacidades e destrezas" (GADELHA, 2009, p. 146), em que, na argumentação dos teóricos, "neoliberais da Escola de Chicago o trabalho aparece como uma abstração" (GADELHA, 2009, p. 149). 
Desde 2016, de forma mais acentuada, a educação pública vem se tornando alvo de ferrenhas críticas conservadoras, acusando os professores de doutrinadores esquerdistas, atacando as universidades, produzindo uma inquisição contemporânea tupiniquim. Longe desses embates serem do nível teórico, é por práticas violentas que esses discursos conservadores vão ganhando forma, através de teorias conspiratórias e sem comprometimento e rigor científico. É partindo desse pressuposto, que este ensaio teórico busca pensar o campo da discussão teórica como igualmente político, corroborando a produção de saberes que possam se tornar performativos, criar ações. Tecer problemas, sem objetivar conclusões, pensar nosso presente.

Temos como objetivo tecer considerações teóricas sobre a racionalidade neoliberal, nutrindo-nos das contribuições de Michel Foucault, da mesma maneira, pensamos junto com Sylvio Gadelha as relações do neoliberalismo com a educação. Por fim, discutimos, de forma introdutória, como os programas "Future-se" e "Novos Caminhos" abraçam o empreendedorismo e a competitividade articulando noções que se movimentam em uma rede discursiva, trabalhando na produção do sujeitoempreendedor, funcionando como aparatos e tecnologias de subjetivação que produzem precariedade.

\section{O NEOLIBERALISMO EM FOUCAULT: EFEITOS DE UMA RACIONALIDADE DE GOVERNO}

Em seu repertório teórico, Michel Foucault vai por meio da genealogia e da arqueologia, ambas funcionando para ele como uma caixa de ferramenta teóricometodológica, em que se nutre sua produção conceitual, pensar as relações de saber e de poder e os modos pelos quais nos tornamos quem estamos sendo. Sua genealogia do poder sobre a sociedade de soberania e sociedade disciplinar evidenciou como funcionou, desde o século XIX, técnicas de produção do sujeito, processos nos quais sujeições foram fabricadas e corporificadas. Sua arqueologia do saber rompe com o cogito cartesiano e anuncia a morte do homem produzido pela modernidade, mostrando igualmente como os universais são efeitos de verdade naturalizados, reverberações de tessituras discursivas que sempre estão em disputas produzindo relações de poder.

A biopolítica, conceito pensado por Foucault para explicitar a forma como poder funcionou na modernidade, vai contribuir em nosso caminho teórico para pensar o neoliberalismo, possibilitando compreendê-lo como uma racionalidade que articula uma sofisticação do poder biopolítico. Esse regime de poder, o biopolítico, se consolidou modificando-se da forma da sociedade de soberania, na qual funcionava práticas de governo que incidiam sobre o indivíduo. A modernidade, como uma sociedade disciplinar, em contrapartida, por meio da biopolítica, fez funcionar um conjunto de técnicas não apenas de disciplinarização, mas produziu igualmente técnicas de regulamentação, possuindo como alvo e instrumento um conjunto de indivíduos: a população.

Foucault vê a população como um "[...] novo corpo: corpo múltiplo, corpo com inúmeras cabeças, se não infinito pelo menos necessariamente numerável" (FOUCAULT, 1999, p. 292), em que várias técnicas disciplinadoras e regulamentadoras vão articular o gerenciamento da vida, produzindo: 
SILVA, R. G. da; RODRIGUES, A. F. F.; FERNANDES, D. P. da S.; ALVES, K. M. da C. V.

[...] cada vez menos o direito de fazer morrer e cada vez mais o direito de intervir para fazer viver, e na maneira de viver, e no "como" da vida, a partir do momento em que, portanto, o poder intervém sobretudo nesse nível para aumentar a vida, para controlar seus acidentes, suas eventualidades, suas deficiências (FOUCAULT, 1999, p. 295).

É através de um fazer viver e um deixar morrer que a biopolítica estima a regulamentação da vida, a população, nesse sentindo, é para o poder biopolítico um "[...] problema social, como problema a um só tempo científico e político, como problema biológico e como problema de poder" (FOUCAULT, 1999, p. 293).

O liberalismo emerge das análises do teórico como uma racionalidade que produz práticas de governo das populações, assim como a condução das suas condutas. O Estado será para o liberalismo lócus de disputas discursivas. Nesse sentido, o Estado para Foucault, é concebido como efeito de práticas de governo, sendo assim governamentalizado, pois:

\begin{abstract}
a governamentalização do Estado foi o fenômeno que permitiu ao Estado sobreviver. Se o Estado é hoje o que é, é graças a esta governamentalidade, ao mesmo tempo interior e exterior ao Estado. São as táticas de governo que permitem definir a cada instante o que deve ou não competir ao Estado, o que é público ou privado, o que é ou não estatal, etc.; portanto, o Estado em sua sobrevivência e em seus limites, deve ser compreendido a partir das táticas gerais de governamentalidade (FOUCAULT, 1979, p. 292).
\end{abstract}

O governo vai ser para Foucault a ação de conduzir as condutas, afirmando igualmente que essa noção de governo não deve ser entendida "[...] seguramente não no sentido estreito e atual de instância suprema de decisões executivas e administrativas em um sistema estatal [...]" (FOUCAULT, 2009, p. 21), incitando, dessa maneira, pensá-la "no sentido largo e antigo de mecanismos e procedimentos destinados a conduzir os homens, a dirigir a conduta dos homens, a conduzir a conduta dos homens" (FOUCAULT, 2009, p. 21).

É partindo dessas articulações sobre o liberalismo, que o teórico vai pontuar que ele não é: "nem uma ideologia nem um ideal. É uma forma de governo e de racionalidade governamental muito complexa" (FOUCAULT apud AVELINO, 2016, p. 248). Sendo necessário efetuar estudos em torno de "[...] como essa racionalidade política pôde funcionar, sob qual preço e usando quais instrumentos" (FOUCAULT apud AVELINO, 2016, p. 248).

Através dessa preocupação teórico-metodológica, Foucault, ao longo de seus cursos no Collége de France entre 1975 e 1980, apresenta o liberalismo como ações práticas governamentais, constituindo novos modos, cada vez mais aperfeiçoados, de sujeitamento. Tal racionalidade produz, por meio de exercícios biopolíticos, ações práticas de condução das condutas, sendo a racionalidade pensada nessa direção, a partir de Nildo Avelino, como "[...] sempre uma ação orientada racionalmente para determinado fim. Racionalidade é uma ação na qual existe a mais perfeita e eficaz articulação entre os meios empregados para atingir um fim almejado" (AVELINO, 2016, p. 248). 
É através de um caminho genealógico que Foucault vai empreender uma investigação do ordoliberalismo alemão e do neoliberalismo americano da Escola de Chicago. Diferente da forma do liberalismo, em sua proposta de Estado de bem-estar social, as duas correntes que se consolidaram em contraposição ao liberalismo clássico no século XX vão, de um lado, no caso do ordoliberalismo, trabalhar sua perspectiva pensando a economia de mercado organizada no interior de "[...] quadros institucionais ou jurídicos que, por um lado, oferecesse as garantias e as limitações da lei e, por outro, assegurasse que a liberdade dos processos econômicos não produzisse distorção social" (FOUCAULT, 1997, p. 95); e, do outro, no que chamamos de neoliberalismo americano, gestado na Escola de Chicago, visa a "ampliar a racionalidade do mercado, os esquemas de análise que ela propõe e os critérios de decisão que sugere a campos não exclusivamente ou não primordialmente econômicos" (FOUCAULT, 2008, p. 439). No entanto, apesar das especificidades dessas práticas político-econômicas e dessas racionalidades, ambas vão articular a produção de uma nova arte de governar, constituída:

de mecanismos que têm por função produzir, insuflar, ampliar as liberdades, introduzir um "a mais" de liberdade por meio de um "a mais" de controle e de intervenção. Ou seja, aqui o controle não é mais apenas, como no caso do panoptismo, o contrapeso necessário à liberdade. Ele e seu princípio motor (FOUCAULT, 2008, p. 92).

Assim, na arte de conduzir as condutas do neoliberalismo americano, se figuram - lucro e o mercado como eixos mobilizadores de sua racionalidade, seu "homo economicus" funciona estabelecendo interesses pessoais em detrimento de possibilidades coletivas, em que todas as relações cotidianas do habitar o presente se tornam permeadas por uma política de escolha racional e custo-benefício, excluindo de forma veementemente explícita todos os demais valores e interesses. O Estado para esse neoliberalismo é sujeitado ao mercado e sujeito do mercado.

\section{NeOLIBERALISMO E EDUCAÇÃO: DA POTÊNCIA DE INDIVIDUALIZAÇÃO AO SUJEITO- EMPREENDEDOR}

Ainda que Foucault não tenha pensado, ao escrever sobre biopolítica, um debate privilegiado para o campo da educação se abriu. Com isso, acreditamos ser possível inferir alguns desdobramentos através - e com - as publicações escritas pelo teórico, pois é "legítimo e factível posicionar a educação como fator presente e ligado a problemática da biopolítica" (GADELHA, 2009, p. 172). Na busca por compreender efeitos neoliberais no campo da educação, conversaremos, nesta sessão, sobre a produção dos indivíduosempresas, ou melhor dizendo, do sujeito-empreendedor a partir das contribuições de Sylvio Gadelha.

Na obra de Sylvio Gadelha (2009), encontramos o esforço tanto teórico quanto político para responder algumas questões, de maneira introdutória, ligadas ao debate foucaultiano de biopolítica, governamentalidade e racionalidade neoliberal, cultura do empreendedorismo e educação. Ele nos ajuda a pensar sobre as relações de poder que 
são estabelecidas na educação e na vida dos sujeitos que são atravessados nessa relação. Por esse motivo, conversaremos aqui com ele e suas contribuições no que tange à discussão sobre neoliberalismo e educação.

Numa tentativa de criar conexões sobre os enlaces do campo da educação com uma governamentalidade neoliberal, atravessamos "a potência de individualização" (GADELHA, 2009, p. 155) que acaba por tensionar uma política de subjetivação que parece emergir e regular a vida-população de profissionais (da área de educação), estudantes, famílias, território-espaços de educação, bebendo da teoria do capital do humano.

Com efeito, pensar os valores econômicos neoliberais é visualizar estratégias de disseminação de redes de poderes que constituem e instituem "processos e políticas de subjetivação" (GADELHA, 2009, p. 144), com o intuito de transformar "sujeitos de direitos em indivíduos - microempresas - empreendedores" (GADELHA, 2009, p. 144). Projetando o indivíduo não apenas enquanto sujeito de direito, mas, principalmente, como um empreendedor de si. Se ainda preferirem, como destaca Gadelha:

\footnotetext{
[...] as competências, as habilidades, e as aptidões de um indivíduo qualquer constituem, elas mesmas, [...] seu capital; mais do que isso, é esse mesmo indivíduo que se vê induzido, sob essa lógica, a tomar a si mesmo como um capital, a entreter consigo (e com os outros) uma relação na qual ele se reconhece (e aos outros) como uma microempresa; e, portanto, nessa condição, a ver-se como entidade que funciona sob o imperativo permanente de fazer investimentos em si mesmo (GADELHA, 2009, p. 149).
}

Consequentemente, podemos pensar que, dentro de uma perspectiva do neoliberalismo, a educação é tida, enquanto um campo minado empresarial, como prestação de serviços, que necessita estabelecer critérios que produzem políticas de exclusão "de modo que a cada vez mais estabeleçam entre si relações de concorrência" (GADELHA, 2009, p. 151), atuando como um corpo "cibernético, pós-orgânico, póshumano" (GADELHA, 2009, p. 155).

Assim sendo, cria-se, ou melhor, se produz um novo jogo de linguagem: alunoempreendedor e professor-investidor. Disso emerge novas metodologias de avaliação, produtividade e rendimento, que se estendem em um tipo de competição que busca estabelecer, nas entrelinhas e foras delas, uma relação de mercado. Em outras palavras, reafirma o papel e função de microempresas do sujeito-empreendedor do campo da educação. Ou melhor, "uma espécie de competição desenfreada, cujo 'progresso' se mede pelo o acúmulo de pontos, como num esquema de milhagem, traduzidos como índices de produtividade" (GADELHA, 2009, p. 156).

Vemos então que, o capital, o que compreendemos cirurgicamente quando falamos "capital", não seria apenas algo externo ao sujeito, e sim, baseado numa premissa da Escola de Chicago, as competências, estratégias e os jogos intrínsecos das relações capitalistas produzem o sujeito-empreendedor sendo este e suas habilidades o próprio "capital". É como olhar-se no espelho e almejar sempre "mais". Um "mais" em forma de investimento de si, no sentido de processo produtivo. Melhor dizendo: "[...] o capital aprende a operar dentro de seu próprio colapso anunciado, [...] prestes a explodir em revoltas e tumultos" (GIUSEPPE e CAVA, 2018, p. 27). 
Desse modo, enxergamos no campo da educação ações permanentes que visam individualizar e, ao mesmo tempo, construir visões coletivas de que se compreender, enquanto um "empreendedor de si", sendo uma potência da individualização ou dito de outra maneira, significa que, para ser bom, mas não apenas isso, para ser o melhor, é preciso um amplo investimento em si mesmo. $E$, nesse caso, não é um investimento na "empresa" como se ela estivesse lá e o sujeito aqui; é um investimento em si, porque você é sua própria empresa, ou seja, "a iniciativa individual e o processo de 'aprender a aprender' são muito mais enfatizados do que o trabalho em equipe" (GADELHA, 2009, p. 158).

Através da ótica neoliberal é disseminada a cultura do empreendedorismo. É preciso ganhar, lucrar. Na verdade, melhor dizendo, lucrar consigo é viver. Ou seja, ganhar torna-se uma condição de vida, investir é vital. Surgem enunciados que apontam que se você não consegue ganhar, lucrar, produzir, é porque não "está pronto" ou "preparado" para ser um sujeito-empreendedor, acionando tecnologias biopolíticas que localizam e interpelam um lugar, um processo de normalização. Logo investir - em si - passa a ser uma necessidade que visa garantir um rendimento, pois:

[...] a cultura do empreendedorismo funciona de modo a fragmentar os indivíduos [...] cada vez menos capazes de se agenciarem entre si em torno da invenção de novos modos de vida, e de intervenção em favor de formas outras de existencialização e de sensibilidade, que não aquelas apregoadas pelo o mercado (GADELHA, 2009, p. 158).

Acionamos, então, o conceito de "precariedade", em Judith Butler (2018), para concordar que, em uma ótica neoliberal, alguns grupos (pessoas LGBTs, mulheres, negras e negros, pobres, indígenas, etc.) "[...] estão ligados por sua repentina ou prolongada sujeição à condição precária, mesmo quando não querem reconhecer essa ligação". Sendo a precariedade, por sua vez, "[...] a distribuição diferencial da condição precária" (BUTLER, 2018, p. 41). Ou seja, "[...] a sociedade civil se torna integralmente um conceito interno à governamentalidade neoliberal" (GIUSEPPE e CAVA, 2018, p. 40) visto que os neoliberais se "dedicaram a forças conservadoras" (GIUSEPPE e CAVA, 2018, p. 18).

Dessa forma, cientes de como práticas neoliberais flertam com autoritarismos que queremos pensar, além de como as forças conservadoras conseguem trilhar planos e projetos que buscam, numa lógica neoliberal, privatizar o campo da educação através de noções como precariedade, desmonte e sucateamento da educação pública, almejamos introduzir algumas questões sobre os programas bolsonaristas "Future-se" e "Novos Caminhos" com 0 intuito de pensar os efeitos excludentes de uma racionalidade neoliberal.

OS PROGRAMAS "FUTURE-SE" E "NOVOS CAMINHOS": REVERBERAÇÕES DE UMA RACIONALIDADE NEOLIBERAL EM SUAS PRODUÇÕES EXCLUDENTES E CONSERVADORAS

A racionalidade neoliberal vai de encontro à educação como uma maquinaria em que os poderes operam para constituição dos sujeitos do neoliberalismo. Nesse sentido, longe de um olhar analítico, almejamos tecer algumas considerações sobre os programas 
SILVA, R. G. da; RODRIGUES, A. F. F.; FERNANDES, D. P. da S.; ALVES, K. M. da C. V.

do governo Bolsonaro denominados 'Programa Institutos e Universidades Empreendedoras e Inovadoras - Future-se' e 'Novos Caminhos', também no âmbito do governo federal, voltados para o ensino técnico, buscando perceber quais efeitos podem ser produzidos por meio de ambas propostas a partir de suas engrenagens neoliberais.

Vemos o programa "Future-se" como discurso de projeção para o futuro, sendo assumido como a grande contribuição da proposta, futuro esse que só se apresenta possível mediante a uma precisa mudança na gestão financeira das Instituições de Ensino Superior - IES do país. Abraça, então, dessa maneira, com objetivo certo de "fortalecimento da autonomia administrativa, financeira e de gestão das Instituições Federais de Ensino Superior (Ifes), por meio de parceria com organizações sociais e do fomento à captação de recursos próprios", como exposto pelo Ministério da Educação. Possuindo, igualmente, o empreendedorismo como um dos eixos basilares de sua conformação.

"Novos Caminhos", o segundo programa acima mencionado, pode ser definido como um aglomerado de ações que tem como propósito um grande "investimento" financeiro na área de educação profissional e tecnológica. Estruturado pelo atual Ministério da Educação, é dividido em três eixos: gestão e resultados, articulação e fortalecimento, inovação e empreendedorismo. Sobre isso, iremos nos ater ao último eixo citado, compreendendo a indução de uma racionalidade neoliberal da qual estamos discutindo neste ensaio.

Construídos sobre a premissa de um investimento que objetiva viabilizar uma relação do setor público-privado movimentando tecnologias biopolíticas de regulação que projetam efeitos de verdade e dialogam com a noção de "cultura do empreendedorismo", eixo que ambos programas abraçam, reiteram a produção de um processo de subjetivação constituído no campo da educação sobre determinados corpos e sujeitos. Sendo essas estratégias de governo articuladas com - e através de - uma governamentalidade neoliberal. Em outras palavras: “[...] uma armadilha" (BUTLER, 2018, p. 47) neoliberalista que projeta a ficção e regulação de "[...] um modo desejável de vida". (BUTLER, 2018, p. 47).

Certa regularidade discursiva permeia os dois programas, que, sempre buscando constituir uma inteligibilidade, naturalizam a competitividade e empreendedorismo como eixos de atuação e funcionamento. No "Future-se", o MEC propõe um maior acirramento de competição entre os departamentos das IES, bem como rompe com a autonomia universitária prevista na Constituição Federal, propondo, em contrapartida, uma "nova autonomia financeira". No "Novos Caminhos", os alunos são estimulados a cada vez mais se aterem ao empreendedorismo de si, fazendo da formação pedagógica uma gama de disputas e competitividade que só produzem precariedade e exclusão. Isso porque, como nos afirma Dardot e Laval:

o neoliberalismo combina a reabilitação da intervenção pública com uma concepção do mercado centrada na concorrência, cuja fonte, como vimos, encontra-se no spencerismo da segunda metade do século XIX. Ele prolonga a virada que deslocou o eixo do liberalismo, fazendo da concorrência o princípio central da vida social e individual, mas em oposição à fobia spenceriana de Estado, reconhece que a ordem de mercado não é um dado da natureza, mas 
um produto artificial de uma história e de uma construção política (DARDOT e LAVAL, 2016, p. 70).

Neste ensaio, a partir de uma perspectiva foucaultiana, buscamos elucidar como os discursos do progresso produzem certa formação discursiva que clamam pelo futuro, assim como esses discursos produzem certa racionalidade neoliberal. Podemos, nesse sentido, indagar: como corpos precários/precariados olham para os discursos que são produzidos pelos programas "Future-se" e "Novos caminhos"? Ou melhor dizendo, quais corpos e subjetividades são produzidos pelo discurso da inovação e do progresso? A visão utilitarista da ciência, expressa nos documentos de apresentação dos programas, evidencia como os pesquisadores devem atuar e produzir suas pesquisas: muitas das maiores empresas nasceram nas universidades e o Brasil vai ficar de fora dessa? 0 conhecimento e o capital humano nossas IES já têm. O que nos resta? Mais empreendedorismo, mais inovação, mais parcerias privadas! Quais efeitos são produzidos nessa nova razão do mundo?

Poderíamos dizer que tais discursos estão articulados para a constituição de um modo para habitar esse futuro, produzindo subjetividades, corpos precários que abraçam os dizeres que foram instituídos por um certo lugar de poder, ou seja, programas instituídos pelo Ministério da Educação e validados pelas Instituições de Ensino Superior. Quais riscos corremos ao adequarmos nossos corpos precários a esse futuro? Longe de um Estado de bem-estar social, encontra-se a educação. Um Estado que opera na racionalidade neoliberal compreende que a ausência de políticas de financiamento para educação nos impulsiona para o futuro. Alinhados à PEC 95/ 2016, os programas "Future-

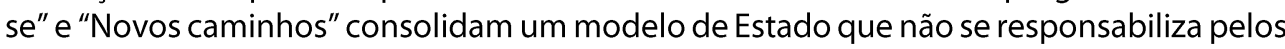
investimentos às pesquisas desenvolvidas pelas IES. Desse modo, as Organizações Sociais e as Instituições Privadas se responsabilizariam pelos investimentos dessas pesquisas, que, até então, são financiadas por instituições públicas de fomento à pesquisa. A partir disso, questionamos novamente: quais pesquisas seriam produzidas para atender as necessidades de um Estado Neoliberal? Quais pesquisadores poderão desenvolver suas pesquisas? Quais objetos do conhecimento serão manipulados? Quais saberes serão produzidos e visibilizados?

Ao alinhar-se a uma concepção conservadora de produção científica, política, cultural, econômica e social, projetos de governo neoliberais criam polícias e normas, que visam regular, através de dispositivos de controle, diversas produções acadêmicas, dentre elas, os estudos de gênero e sexualidades, retirando-os de uma esfera do aparecimento, "[...] uma vez que o campo de aparecimento é regulado por normas de reconhecimento que são hierárquicas e excludentes" (BUTLER, 2018, p. 46), e inviabilizando debates, bem como "[...] um conjunto de reivindicações sobre o direito de ser reconhecido e de ter uma vida vivível" (BUTLER, 2018, p. 48), de determinados segmentos da sociedade.

Dessa maneira, temas como biopolítica, governamentalidade e neoliberalismo incidem "[...] diretamente sobre os processos de inclusão-exclusão (ou de exclusão por inclusão)" (GADELHA, 2009, p. 214), assim sendo, [...] deve vir a interessar cada vez mais aos educadores e aos teóricos da educação, permitindo-lhes avaliar como e em que medida suas práticas se encontram implicadas nesses processos" (GADELHA, 2009, p. 214). 
SILVA, R. G. da; RODRIGUES, A. F. F.; FERNANDES, D. P. da S.; ALVES, K. M. da C. V.

\section{CONSIDERAÇÕES FINAIS}

Este ensaio teórico não objetivou conclusões, pelo contrário, vê nesses nossos dias importantes dispositivos constituindo novas inteligibilidades, em que 0 neoliberalismo entrava disputas mercadológicas e conservadoras na educação visando a instituir sua materialidade e a naturalização de suas práticas. A partir dessa racionalidade, e em nossas notas tensionadas, vemos a teorização também como um lugar político, produzindo contra produções que corroborem, no desarticular, tais dispositivos e possibilitem a produção e articulação de novas práticas de resistência que intentem contra essa nova razão do mundo.

Artigo recebido em: 09/11/2019 Aprovado para publicação em: 11/02/2020

\section{NEOLIBERALISM AND EDUCATION: NOTES OF AN EXCLUSIONARY RATIONALITY}

ABSTRACT: This theoretical essay aims to problematize neoliberalism from the contributions of Michel Foucault, understanding it as a rationality that articulates a sophistication of biopolitical power. It launches notes that aim to problematize recent events in our country, increasingly realizing neoliberal agendas expanding within the field of education under the signs of progress and innovation, where the "Future-se" and "Novos Caminhos" of neoliberal programs, on the one hand it articulates the defense of a privatization and the denationalization of public education and on the other it fosters conservative and authoritarian ideas and practices.

KEYWORDS: Neoliberalism. Education. Conservatism. Foucault.

\section{NEOLIBERALISMO Y EDUCACIÓN: NOTAS DE UNA RACIONALIDAD EXCLUYENTE}

RESUMEN: Este ensayo teórico tiene como objetivo problematizar el neoliberalismo a partir de las contribuciones de Michel Foucault, entendiéndolo como una racionalidad que articula una sofisticación del poder biopolítico. Lanza notas que apuntan a problematizar los eventos recientes en nuestro país, realizando cada vez más agendas neoliberales que se expanden dentro del campo de la educación bajo los signos de progreso e innovación, donde el "Future-se" y los "Novos Caminhos" como programas neoliberales bolsonaristas, por un lado articula la defensa de una privatización y la desnacionalización de la educación pública y por el otro fomenta ideas y prácticas conservadoras y autoritarias.

PALABRAS CLAVE: Neoliberalismo. Educación. Conservadurismo. Foucault.

\section{REFERÊNCIAS}

AVELINO, Nildo. Foucault e a racionalidade (neo)liberal. Revista Brasileira de Ciência Política, Brasilia, n.21, set./sez., 2016. Disponível em: 
http://www.scielo.br/pdf/rbcpol/n21/2178-4884-rbcpol-21-00227.pdf. Acesso em: 10 ago. 2019.

BUTLER, Judith. Corpos em aliança e a política das ruas: notas para uma teoria performativa de assembleia. Tradução de Fernanda Siqueira Miguens. $1^{\text {a }}$ ed. - Rio de Janeiro: civilização Brasileira, 2018.

DARDOT, Pierre; LAVAL, Christian. A nova razão do mundo: ensaio sobre a sociedade neoliberal. Tradução de Mariana Echalar. São Paulo, Boitempo, 2016.

FOUCAULT, Michel. Em defesa da sociedade: curso no Collège de France (1975-1976). Tradução de Maria Ermantina Galvão. São Paulo, Martins Fontes, 1999.

FOUCAULT, Michel. Microfísica do poder. Tradução de Roberto Machado. Rio de Janeiro, Graal, 1979.

FOUCAULT, Michel. Do governo dos vivos: Curso no Collège de France, 1979-1980: aulas de 09 e 30 de janeiro de 1980. Tradução, transcrição e notas de Nildo Avelino. São Paulo, Centro de Cultura Social, 2009.

FOUCAULT, Michel. Nascimento da biopolítica: curso no Collège de France 1978-1979. Tradução de Eduardo Brandão. São Paulo, Martins Fontes, 2008.

GADELHA, Sylvio. Biopolítica, governamentalidade e educação: introdução e conexões a partir de Michel Foucault. Belo Horizonte, Autêntica Editora, 2009.

GIUSEPPE, Cocco; CAVA, Bruno. Enigma do disforme: neoliberalismo e biopoder no Brasil global. 1. ed., Rio de Janeiro, Mauad X, 2018.

ROBSON GuEDES DA SILVA: Doutorando em Educação pelo Programa de Pós-Graduação em Educação (PPGE-UFPE). Mestre em Educação pela Universidade Federal de Pernambuco (PPGE-UFPE). Graduado em Pedagogia pela Universidade Federal de Pernambuco (CEUFPE). Faz parte do Grupo de Estudos e Pesquisas Foucault e Educação (GEPFE-UFPE). Atualmente é Professor Substituto do Departamento de Educação da Universidade Federal Rural de Pernambuco (DEd-UFRPE).

Orcid: https://orcid.org/0000-0003-0165-1430

E-mail: robsonguedes00@hotmail.com 
SILVA, R. G. da; RODRIGUES, A. F. F.; FERNANDES, D. P. da S.; ALVES, K. M. da C. V.

Ana Flor Fernandes Rodrigues: Graduanda em Pedagogia pela Universidade Federal de Pernambuco (UFPE). Faz parte do Grupo de Estudos e Pesquisas Foucault e Educação (GEPFE-UFPE).

Orcid: https://orcid.org/0000-0002-1856-5750

E-mail: contatoanaflor@outlook.com

Diogo Pedro da Silva Fernandes: Mestrando em Educação pelo Programa de PósGraduação em Educação (PPGE-UFPE). Graduado em Pedagogia pelo Centro Universitário Maurício de Nassau (UNINASSAU). Faz parte do Grupo de Estudos e Pesquisas Foucault e Educação (GEPFE-UFPE).

Orcid: https://orcid.org/0000-0003-0726-6963

E-mail: dpsfernandes@outlook.com

Karina Mirian da Cruz ValençA Alves: Doutora em Educação pela Universidade Federal de Pernambuco (PPGE-UFPE). Professora do Departamento de Métodos e Técnicas de Ensino (DMTE-UFPE), e do Programa de Pós-Graduação em Educação (PPGE-UFPE) da Universidade Federal de Pernambuco. Coordenadora do Grupo de Estudos e Pesquisas Foucault e Educação (GEPFE-UFPE).

Orcid: https://orcid.org/0000-0002-1111-2126

E-mail: karinamirian@gmail.com

Este periódico utiliza a licença Creative Commons Attribution 3.0, para periódicos de acesso aberto (Open Archives Iniciative - $O A I$ ). 